\title{
Violência: A Pressão Sócio-Econômica ${ }^{(*)}$
}

\author{
Georgette Nacarato Nazo \\ Professora-Assistente-Doutora Colaboradora \\ no Departamento de Direito Internacional \\ da Faculdade de Direito da Universidade \\ de São Paulo
}

\begin{abstract}
SUMARIO: 7. Introdução - 7.1. A pressão social como causa primeira a gerar fatores de violência - 7.1.1. Modificasōes do comportamento humano: A) Nacionalidade; B) Cultura - 7.1.2. Reacão individual ou coletiva - 7.2. A pressão econômica concausa geradora de violência 7.2.1. A economia moderna e seu fracasso -- 7.2.2. O desvalor do homem - 7.2.3. A impermeabilidade das instituicōes a mudansas - 7.2.4. O abuso do poder económico - 7.3. Solucões viâveis - 7.3.1. Modificações estruturais necessárias à diminuição dos indices de violência - 7.3.2. o humanismo na melhoria duas condições da qualidade de vida.
\end{abstract}

\section{Introdução}

Pretender analisar o bem-estar da humanidade, eliminando-se os fatores que lhe são adversos, é campo próprio da Sociologia, obrigando-a a investigar as formas da organização social que não limitam as pessoas, mas que possibilitem ao indivíduo tomar suas decisões quanto às suas próprias ações.

Dentro de tal colocação, afloram os problemas da situação humana, originando-se desta os problemas morais.

Seria, portanto, muito significativo indagar-se: - Deve, um grupo social, estar em posição inferior a outro grupo?

Semelhante indagação estrutural leva-nos a perquirir, dentro do objeto de nossa contribuição ao estudo dos fatores sócio-econômicos da violência, sobre a causa primeira: a pressão sócił-econômica exercida por indivíduos, grupos ou instituições sobre outros tantos indivíduos, grupos e sociedade, gerando e desenvolvendo fatores de criminalidade.

Com efeito, a sociedade hodierna e seu regime econômico geram, favorecem e desenvolvem fatores de pressão sobre os indivíduos, pressão esta que é a causa eficiente da intranqüilidade, insatisfação do

(*) Palestra proferida no auditório da Associação dos Diplomados na Escola Superior de Guerra, Delegacía de São Paulo, como contribuição ao tema do Ciclo XXIII, em outubro de 1981, sobre a violência e suas causas. 
homem comum, cuja agressividade latente, própria a seus anseios de auto-realização, poderá desencadear todo um procedimento anti-social, pelo acúmulo de frustrações do berço à puberdade e desta à obtenção de um espaço social.

\subsection{A pressão social como causa primeira a gerar fatores de violência}

A experiência da História Moderna das civilizações tem revelado que, tanto nos regimes econômicos liberais, como nos centrados, todo o homem, no anseio de suprir suas necessidades básicas, no desejo de alcançar seus objetivos vitais, nada mais tem feito do que diminuir seu semelhante a qualquer preço e por quaisquer meios.

Assiste-se à exploração do homem pelo homem, em todos os setores, a despeito de se pretender valorizá-lo, pois o humanismo tem ficado em meras abstrações.

Da parte dos governantes, mascaram-se programas de benefício à saúde, de atendimento ao economicamente fraco e o resultado a que se chega é desalentador. Uns acumulam bens materiais, nem tanto por esforço próprio e, sim, como conseqüência de trabalho e do sacrifício de outrem; certas políticas do governo desatendem às importantes necessidades mínimas do indivíduo, grassando a fome, a miséria, a pobreza, fatores de criminalidade, de violência à sociedade.

É bem verdade que vivemos numa sociedade instável mutável, egocêntrica, consumista, onde o tecnicismo aprimorado da comunicação visual contamina o indivíduo.

As instituições parecem, no dia a dia, impermeáveis às necessárias transformações que atendam à realidade social.

Os poderes constituídos, distanciados dessa mesma realidade, editam normas que, naturalmente, são descumpridas por todos, porém só aos humildes são aplicadas sanções, pois os mais poderosos, por desfrutarem dessa condição humana privilegiada, ficam incólumes.

Repetimos, sem qualquer apego marxista, o homem é explorado pelo homem.

Conseqüentemente, tanto a pressão social, como a econômica e a política introduzem modificações no comportamento do homem que, por sua vez, modifica a organização social e sofre o retorno dessas alterações.

\subsubsection{As modificações do comportamento humano: Nacionalidade - Cultura}

Influenciam as modificações do comportamento humano:

A) A NACIONALIDADE: Porquanto os objetivos imediatos de uma Nação quer políticos, quer econômicos, trazem um impacto sobre 
a vida de cada cidadão. É notória a diferença das condições de vida em país conturbado por guerras externas e num país, por tradição, pacífico ou pacificador. Naquele, o cidadão refreia determinados sentimentos e reage de forma agressiva num convivio social, embora o aprimoramento da técnica bélica crie a necessidade correlata do aprimoramento da cultura, mercado de trabalho para técnicos, melhorando as condições de vida de determinadas famílias. Já num país pacífico, onde inexiste o perigo de guerras, o indivíduo se realiza de um modo mais tranqüilo, como na Suiça, ou mais acomodado, como no Brasil.

Incito ao prolema da nacionalidade está o racismo. As dissenções étnicas conservam traços diferenciados e, num país como o nosso, a amálgama de índios, negros, estrangeiros que aqui aportaram, deixou na miscigenação, contornos diversos, não se podendo cogitar, ainda, de um caráter nacional.

Existe uma especificidade para cada Nação, pelas suas caracte. rísticas étnicas, histórico-culturais que lhes imprimem um estilo de vida. O Brasil incorporou hábitos, costumes importados, tendo bem pouco de genuíno.

$\mathrm{E}$, se a pretexto da colonização inicial, favoreceu indiscriminada entrada de estrangeiros que muito contribuíram para o crescimento do país, hoje, a sociedade brasileira sente, em diversos pontos do território nacional, existir um confinamento de certos grupos, já filhos daqueles estrangeiros, mas que, por conservarem apego à língua de origem de seus pais, às suas tradições, constituem focos de dificuldades a uma verdadeira integração nacional.

B) CULTURA: O acervo de conhecimento e das tradições de um povo, a comunicação, o acúmulo de experiências vividas pela humanidade, permitem ao indivíduo atualizar-se a nível global de aprendizagem, não só individual, como de todo o corpo social.

Para que isto ocorra em benefício da sociedade, é imprescindivel a educação familiar e escolar de todas as camadas da população de um país. O acesso de todos à escolaridade permitirá eliminar as diferenças entre os grupos sociais, diferenças estas geradoras de agressividade e violência.

Podem, as organizações sociais, quer uma simples associação, um clube, uma igreja, um partido político constituir um esforço conjugado de pessoas com um objetivo comum. O indivíduo despersonaliza-sē, por um ângulo, mas participa do todo, porque encontra nas mesmas, um equalitário e adequado tratamento.

No Brasil, semelhante fenômeno ocorreu, de início, por obra dos missionários. Hoje, inúmeras são as associações existentes, com objetivos os mais variados. No entanto, barreiras são colocadas em certos 
setores, quer na discriminação racial, punível, como reza a Constituição Federal em seu artigo $153 \S 1^{\circ}$, segunda parte, bem como na discriminação financeira.

\subsubsection{Reacão individual ou coletiva}

Existindo pressão social que impeça o indivíduo de participar dos sentimentos de nacionalidade, da cultura, das organizações sociais, construindo e modificando o caráter nacional e integrando, efetivamente, os objetivos da nacionalidade, é claro que a reação só pode ser contrária, pejorativa mesmo.

Passa, o indivíduo, a agir conforme os seus interesses, os seus valores e fins, naquele estado de confusão, em situação de anomía, como relembra Durkheim. Afasta-se das regras de conduta social, pela insatisfação, pela intranqüilidade em que se encontra, pela importância do "seu mundo em face do que só pode conquistar com violência."

Com efeito, num país como o nosso, de tão grande extensão territorial, onde é notória a dicotomia de crescimento e desenvolvimento em suas latitudes, encontramos na Constituição Federal as determinações expressas para todos, no sentido de assegurar aos brasileiros e estrangeiros aqui residentes, a inviolabilidade dos direitos concernentes à vida, à liberdade, à segurança e à propriedade, pois todos são iguais perante a lei, sem distinção de sexo, raça, trabalho, credo religioso e convicções políticas (artigo $153 \S 1^{\circ}$ ).

A mesma Carta Magna, em seu artigo 175, cuida da proteção da família pelos Poderes Públicos e no artigo 176, da educação como direito de todos, como um dever do Estado, dado no lar e na escola.

Todavia, se o texto constitucional é amplo, na inviolabilidade de tais direitos, o Código Civil enumera os deveres recíprocos de pais e filhos (artigo 231 em seus 4 incisos), ressaltando a importância da educação, complementando, o Código Penal, em tipificar os crimes contra a assistência da família (artigos 244/7).

Não podia, é claro, um texto de lei falar em amor. Mas cabe à família, tradicionalmente, a educação da prole, transmitindo-lhe 0 patrimônio cultural e moral da sociedade, que, num país como o nosso, inspira-se em preceitos morais cristãos, naquela caridade, naquele amor ao próximo que, tanto crentes como não crentes, procuram transferir a seus filhos.

A simples procriação, para garantia da sobrevivência biológica, distanciada dos valores afetivos e de compreensão, é que tem colocado em crise a institução familiar, gerando frustrações individuais de seus membros em dois aspectos: o intrapunitivo e o extrapunitivo. No primeiro, o indivíduo se revolta contra si mesmo, aliviando sua tensão, pela "catarse"; no segundo revolta-se contra o mundo exterior, ou 
naquilo e naqueles mais próximos de si, dentro do lar, ou, numa fase mais aguda, contra toda a sociedade gratuitamente.

Ora, a carência afetiva no lar, somada à falta de integração na sociedade, onde se nega ao individuo igualdade de oportunidades na conquista dos meios essenciais de subsistência só pode acarretar-lhe desordem, revelada no comportamento desviante, pondo em risco a segurança pessoal e o patrimônio alheio.

Não lhe abrindo, a sociedade, os meios necessários a se autoafirmar, num contexto familiar, e de se manter, pelo trabalho dígno e dignificante, tão bem lembrado nas Encíclicas Papais, num contexto global, a conseqüência será a exacerbação da agressividade.

Sem instrução, sem escolaridade, sem ofício, convivendo num meio inadequado, abraçando fome, subnutrição, vícios, convivendo, lado a lado, com outros seres nas mesmas condições, certamente partirá para um outro tipo de organização anti-social: a senda do crime que melhor se ajuste a seus valores e fins. Toma as suas decisões livremente, embora contrariando a ordem sócio-jurídica institucional.

\subsection{A pressão econômica concausa geradora de violência}

Vinculada à pressão social, a econômica tem trazido, nos dias que correm, inúmeros fatores que favorecem, criam e desenvolvem a criminalidade.

\subsubsection{A economia moderna e seu fracasso}

Com efeito, toda a economia moderna, voltada para a aritmética, contabilização e solvabilidade de valores materiais, não tem conexão unívoca e determinada entre as exigências existencias dos seres humanos. Embora procurando uma ordem na construção do homem pelo homem, através do preparo e emprego de coisas contabilizáveis por toda espécie de contabilidades em calorias, em preços fictícios ou programados com correções, a imagem e modelo do homem fica na dependência do nível e das qualidades dos diálogos sociais.

Se estamos, hoje, no pleno desenvolvimento de todos os recursos, os naturais tornados disponíveis, em capital aumentado pelo investimento privado, estimulado e orientado pelo investimento público, somente com a total valorização de todas as energias humanas, utilizando-se os cálculos de forma positiva para uma distribuição equânime de rendas, é que se terá uma economia voltada realmente às exigências existenciais do homem.

Enquanto determinados grupos sociais concentrarem poder e riquezas em suas mãos, negando a outros grupos menos favorecidos uma participação atuante através do trabalho justamente remunerado, haverá um favorecimento à revolta social, um incitamento à violência. 
$\mathrm{E}$ dizemos justamente remunerado, como colorário do direito ao trabalho, inserido em preceito constitucional (artigo 165), contribuindo para o desenvolvimento da Nação e obtendo para si e sua família, a segurança econômica, através do salário para satisfação de suas exigências vitais.

Pela circunstância de se viver em harmonia dentro de um contexto internacional, a segurança de uma Nação e conseqüentemente de seu povo, está intimamente ligada ao desenvolvimento, e ao invés de se criar um modelo próprio, adequado às exigências existenciais de seu povo, importam-se idéias, técnicas e sofisticações de países mais desenvolvidos, por vezes avessas à índole deste povo e às suas condições de vida.

Resta claro, que a estrutura social é afetada até certo ponto, por outras alienígenas. Mas, a permissividade consciente dos governantes em apenas copiarem modelos estrangeiros scb a égide do desenvolvimento é que tem propiciado aos países de sistema capitalista gravitar em torno da dominação central dos Estados Unidos da América e aos de economia centrada, na órbita da Rússia.

\subsubsection{O desvalor do homem}

Coloca-se, o Brasil, entre os primeiros, incorporando técnicas e sofisticações próprias a uma sociedade de consumo que transforma o homem em objeto deste consumo.

A pressão econômica revela-se na circunstância de que o homem ao se transformar em objeto consumidor, deixa de ser trabalhador incentivado a produzir, para ser consumidor, incentivado a consumir.

O amparo que as instituições econômico-financeiras dão à publicidade e à produção massiva e repetitiva da ideologia consumista é infinitamente superior ao embasamento econômico e financeiro que o trabalhador percebe numa sociedade estatal e capitalista.

Ora, num território imenso, com características regionais díspares, onde a cultura e a educação são privilégio de alguns mas a pobreza é de muitos, a sociedade de consumo, imediatista, egoísta, cuja meta é a satisfação iminente, cria as condições para o delito por contágio hierárquico.

O espírito de imitação dos hábitos desta sociedade, afortunadamente impune, divulgados pelos meios de comunicação permite à população mais carente, um comportamento desviante das regras da ordem jurídica institucional, pela crença de que tais hábitos não padecem de sanção.

\subsubsection{A impermeabilidade das instituições a mudanças}

Alie-se, a isto, a impermeabilidade das instituições a mudanças mais profundas, vez que, reconhecidamente, ineficientes os meios de controle social. 
Com efeito, determinadas camadas da sociedade colocam, como objetivo intrínseco da educação infantil, o lucro e, deste, o trabalhador é alijado, pelo achatamento salarial, em relação ao custo de vida sempre crescente, ou pior ainda, pelo subemprego ou pelo desemprego. Semelhante indivíduo é, por si só, um candidato em potencial a gerador e vítima não só de sua própria violência, como também, dos meios repressivos, ora ostensivos, ora mascarados através de sanções econômicas, impostos pelo Estado de características paternalísticas e pelas instituições que apóiam este mesmo Estado, como forma de continuarem, de prosseguirem impunemente.

Ao lado de um enxurrilho de leis em que se buscam definir os tipos de crimes e sanções correlatas, todo o aparelho policial-judiciário encontra razão de funcionamento quado o agente criminoso é o homem comum. Se abastado, se detentor de poderío econômico, há inúmeros subterfúgios para a exclusão de punibilidades.

\subsubsection{O abuso do poder econômico}

Merece, também, consideração dentro desta linha de raciocínio, o abuso do poder econômico, cuja repressão é contemplada no artigo 160 inciso V de nossa Constituição Federal.

Apesar da existência de lei específica anti-trust como, a de $\mathrm{n}^{\circ}$ 4.137 de 10-09-1962, regulamentada em 1963, o direito brasileiro tem feito ouvidos moucos a semelhante legislação, o que tem merecido de doutrinadores a preocupação em tipificar de forma mais incisiva, no Código Penal, o crime e na lei de contravenções as respectivas contravenções societárias.

Objeto do direito penal econômico, tão bem examinado por Manoel Pedro Pimentel, no seu "Direito Penal Econômico", ed. Revista dos Tribunais Ltda., SP, 1973, outras tantas leis como a de Sonegação Fiscal ( $n^{\circ} 4.729$ de 14-07-1965), a de Mercado de Capitais ( $n^{\circ} 4.728$ de 14-07-1965), a de Instituições Financeiras ( $n^{\circ} 4.595$ de 31-12-1964) estão a exigir uma aplicação eficiente, como forma de revelar à sociedade o desejo de perseguir atos delituosos no setor, para que a corrupção não continue a encontrar, tanto no setor privado, como no público, campo fértil de proliferação.

\section{y.3. Soluções viáveis}

\subsubsection{Modificações estruturais necessárias à diminuição dos índices de violência}

Não se erradica, é certo, a violência dentro dos limites geográficos de um país, mormente tendo-se presente a interação das estruturas nacionais e internacionais.

Poder-se-á, isto sim, através da modificação planejada das estruturas sociais e econômicas, com uma política de governo preocupada 
em atender aos objetivos nacionais, diminuir os índices dessa violência, na esteira da Declaração de Caracas, no VI Congresso da ONU sobre prevenção do delito, em 1980: "A contenção da criminalidade está na dependência da melhoria das condições sociais e do nível da qualidade de vida".

Não será pela arbitrariedade daqueles que detêm parcelas do poder nacional, notadamente aqueles que devem exercitar o poder de polícia do Estado que se conseguirá tal desiderato.

Será através da conscientização dos poderes instituídos, da conscientização de toda a comunidade, do favorecimento ao trabalho para todas as gamas da sociedade, permitindo-lhes escolaridade que se poderá forjar a mentalidade de um povo.

O exemplo positivo das mais cultas camadas - quem sabe? a ilusória postura das classes privilegiadas em ver (e não simplesmente olhar) os menos favorecidos como um seu semelhante, digno também de desfrutar de bem-estar, uma política de governo que concilie desenvolvimento com segurança, num justo equilíbrio, possibilitando ajudar aqueles que, por não saberem, porque lhes foi mostrada a luta honesta pelo ganha pão, continuam a viver do crime e da violência.

Sem que se tenha presente a realidade nacional, suas características sócio-econômicas e políticas, de nenhuma valia pretender encetar campanhas de prevenção à criminalidade.

\section{Y.3.2. O humanismo na melhoria das condições da qualidade de vida}

Vivemos, hoje, no Brasil, o que se convencionou chamar de abertura. Pena que se cogite de uma abertura política.

Importante se nos apresenta esta abertura desde que não seja eivada de princípios demagógicos, para que se tenham em mente, os reais valores do homem e especialmente a situação de vida dos brasileiros.

Se, com tal abertura, se conseguisse eficazmente começar a viver democracia, se aqueles mais afeitos às coisas públicas, se determinados segmentos empresariais, contando com a boa disposição dos homens das letras, fizessem revivescer o humanismo que tem ficado, repetimos, em meras abstrações, para algo de concreto, veremos que o país está caminhando em busca dos valores que sempre têm orientado a humanidade, ora com reais vantagens, outras vezes, com evidente fracasso.

O Brasil tem vivido, sobremaneira, no fracasso de atingir seus objetivos nacionais permanentes, especialmente, nestes últimos tempos, dissociada sua gente da escolha daqueles que devem dirigir os destinos da Nação. 
Se, de um lado, os mais ilustrados vivem o inconformismo da falta de eleições, larga margem da população está alheia e alheiada de participar, pois lhe falta o ensino, a educação e a possibilidade de competir. Foram castradas as manifestações de populismo, própria do brasileiro da década de 50, que acreditava na política de então.

Resta claro, que a população carente, assistindo que um grupo mais poderoso sufoca-lhe as perspectivas, só encontra opção, chamando sobre si a atenção da sociedade, no ato de violência em todos os seus matizes.

Caçados para responderem a inquéritos policiais, recebendo a aplicação de penalidades, são depois confinados em prisões, num contágio direto com outros tantos transgressores da lei, apesar de, no Estado de São Paulo, já existirem melhores condições para os presos, numa colocação filosófico-política pioneira, para melhoria da vida e de tratamento dos mesmos.

Não procuram, as instituições, de um modo geral, uma forma de reeducação dos marginais, nem adentram a exames psiquiátricos que resultariam na necessidade de substituir a pena por terapias adequadas à recuperação do ser humano.

Ficam as instituições, estagnadas, sem qualquer empenho nas mudanças que seriam benfazejas à sociedade e que, em última análise, beneficiaria o homem.

Se à pequena sociedade familiar cabe o dever e a responsabilidade de bem estruturar o homem para um convivio social compativel, é de responsabilidade do Estado não permitir que uma pequena minoria monopolística reja a orquestra do povo com a batuta da oligarquia.

Só assim haverá equilíbrio e melhoria nas condições de vida nos diversos rincões deste país.

\section{Bibliografia}

AGUIAR BARROS, José Manoel de - "O Preço da Ordem é Eterno Delito" - in "Folhetim" da Folha de São Paulo, de 30-08-81.

CAdERNOS E ESTUdDOS - Psicologia Experimental I - Textos para fins didáticos.

CIANCI, Salvatore - “Il Vandalismo Dei Giovani: Aspetti Sociologici, Psicologici e Giuridici" - Estratto da "Rassegna Dell'Arma Dei Carabinieri" — Anno de 1980, no 1.

COULSON, Margaret A. e RIDDELL, David - "Introdução Crítica à Sociologia" - 3a Edição - Zahar Editores.

DEBERT, Guita - "Populismo e Democracia" - in "Folhetim" da Folha de São Paulo, de 16-8-1981.

HALL, Jerome - "Delito, Derecho y Sociedade - Causas Sociológicas del Delito" Ed. Depalma, B.A., 1974.

LACROIX, Jean e Outros - "Os homens diante do Fracasso" - Ed. Loyola, 1970.

PERROUX, François - "O Fracasso da Economia Moderna e as Oportunidades de Progresso Humano"

SCHERER, René - "Sobre a Crítica do Humanismo" 
MIELNIK, Isaac - "De Que Modo e Por Que Reagem os Agressivos" - Folha de São Paulo, de 04-09-1981.

NAPOLENTANO, Guido - "Violenza e Trattati Nel Diritto Internazionale", Giuffrè, 1977 Milano.

PIMENTEL, Manoel Pedro - “Direito Penal Econômico" - Ed. Revista dos Tribunais São Paulo, 1966.

PIMENTEL, Manoel Pedro - "Sociedade Crimógena" - Trabalho Apresentado na $33^{\natural}$ Reunião Anual da Sociedade Brasileira Para o Progresso da Ciência, realizada em Salvador-BA, em julho de 1981, publicado no Boletim da Associação dos Advogados de São Paulo, em Suplemento, no 1.182 (Agosto/1981).

PACHECO E SILVA, Antonio Carlos - "A Violência e a Segurança Nacional" - Rev. da Associação dos Diplomados da ESG Ano XXIX, n 183, 1980.

REALE JƯNIOR, Miguel - "Limites e Limitações" - Folha de São Paulo, de 14-06-1981.

SCHIEBER, Benjamin M. - "Abusos do Poder Econômico" - Ed. Revista dos Tribunais São Paulo, 1966.

ONU - VI Congresso Sobre Prevenção do Delito - Caracas, 1980. Constituição da República Federativa do Brasil. Código Civil Penal Execuções Criminais Leis Relativas ao Poder Econômico. 